\title{
El inicio de la recepción cervantina en Alemania: las primeras adaptaciones teatrales del Quijote
}

\author{
CARMEN Rivero IgLESIAS*
}

Todavía en 1892 se jactaba Edmund Fischer de haber descubierto por primera vez una mención al Quijote en un libro en lengua alemana del año $1613 .{ }^{1} \mathrm{Se}$ trata de la descripción del viaje, la boda y el regreso al Palatinado de Federico $\mathrm{V}$ con motivo de sus esponsales con Isabel Estuardo realizada por Tobias Hübner $^{2}$, letrado al servicio del ducado de Anhalt. Es en el marco de estas significativas festividades en el que tiene lugar la primera salida a escena de don Quijote, el 13 de junio de 1613, cuando los recién casados son recibidos jubilosamente en Heidelberg. ${ }^{3}$ Los fastos organizados para tal ocasión se convertirían pronto, nos dice Fischer, en modelo para otros territorios alemanes.

Desde entonces, los estudiosos de la recepción del Quijote en Alemania se limitan a mencionar esta primera aparición de don Quijote en la escena alemana sin ulteriores análisis. Es Briesemeister, en cambio, el que en un artículo reciente llama la atención sobre la importancia de estos primeros espectáculos, poniendo de manifiesto la escasa atención que han recibido por parte de la crítica a pesar de que inauguran la recepción de la obra en Alemania. ${ }^{4} \mathrm{Su}$ conservación posee además un carácter excepcional, por constituir una de las pocas adaptaciones teatrales del Quijote a la lengua alemana que, gracias a la significativa ocasión en la que tienen lugar, se conservan con la crónica festiva y, por lo tanto, no se han perdido. Señala Gabel, en este sentido, que el hecho

* Münster, Alemania

1. Fischer (1892: 331-332).

2. Hübner (1613).

3. A pesar de que esta primera aparición de don Quijote en Alemania se produzca con anterioridad a la primera traducción alemana de la obra cervantina, sostiene Fischer que en la representación se da por sentado que el público la conoce sobradamente. No obstante, las referencias son lo suficientemente autónomas para suscitar comicidad por sí mismas sin que deba necesariamente darse por sentado el conocimiento previo de la obra por parte del público.

4. Briesemeister (2011: 319-328). 
de que las adaptaciones teatrales del Quijote no tuvieran demasiado éxito habría provocado la desaparición de su registro en los archivos editoriales, por lo que hoy su localización se ha tornado muy dificultosa. ${ }^{5}$

Es propósito del presente estudio abordar el análisis de los textos conservados para mostrar en qué medida su carácter pionero los hace fundamentales en la historia de la recepción de la obra cervantina, ${ }^{6}$ al determinar, como se mostrará a continuación, la interpretación de la obra en el XVII alemán. Los textos a los que se hará referencia serán los correspondientes a la ya mencionada primera salida a escena de don Quijote en Heidelberg en 1613 y la adaptación teatral del Quijote para la celebración de un bautizo de la corte en Dessau, organizado por el mismo funcionario, Tobias Hübner y publicada al año siguiente en Leipzig. ${ }^{7}$

La representación de 1613 se recoge bajo el título de «Cartel zum Kübelstechen»». ${ }^{8}$ El término cartel se refiere en el siglo XVII a un acuerdo por escrito de las condiciones de lucha en justas o torneos o el desafío a la lucha plasmado por escrito. ${ }^{9}$ Se trata por tanto de un desafío de don Quijote a un Kübelstechen, es decir, a una lucha de carácter grotesco en la que los participantes no se presentan como caballeros sino como campesinos, con trajes acolchados en lugar de armadura, con un barril en la cabeza en lugar de casco y sobre viejos jamelgos tratando de alcanzarse con un palo. ${ }^{10}$

Don Quijote, presentado en la pieza como un fanfarrón, afirma decididamente que obligará a todos aquellos vencidos por el fuerte valor de su brazo al reconocimiento de los estatutos de la caballería andante, que articula en una enumeración de catorce puntos en los que se hace alusión a distintos capítulos y episodios de la novela cervantina que subrayan el lado ridículo del personaje principal. Don Quijote insta a los vencidos, entre otras cosas, a reconocer la bacía como yelmo de Mambrino o a admitir la belleza de Dulcinea como superior, incluso, a la de Maritornes. La alusión a la belleza de ambas queda relativizada, naturalmente, con la referencia a continuación a Guccio Imbratta, personaje del Decamerón apodado Guccio Porco, proverbial por su fealdad. Los capítulos a los que se hace referencia hacen hincapié, asimismo, en la distorsión de la realidad del personaje principal. Los vencidos deben reconocer, de este modo, que luchar contra molinos de viento en funcionamiento conlleva la misma peligrosidad que luchar contra gigantes. Rocinante debe ser reconocido como el más famoso de la Historia y las locuras realizadas

5. Gabel (2005: 58).

6. Se trata de uno de los testimonios más tempranos de recreaciones cervantinas. Briesemeister hace, en este sentido, referencia a una anterior, El triunfo de don Quixote, que tuvo lugar con motivo de la canonización del fundador de la SJ, San Ignacio de Loyola en 1609 y que Alonso de Salazar recoge en Fiestas que hizo el insigne Colegio de la Compañia de Jesús de Salamanca a la Beatificación del Glorioso Patriarca S. Ignacio de Loyola: con los sermones y poesías, Salamanca: Viuda de A. Taberniel, 1610. Vid. Briesemeister (2010: 95).

7. Briesemeister (2011: 319-328).

8. Hübner (1613: 51-55).

9. Etymologisches Wörterbuch des Deutschen, 1997.

10. Watanabe-O'Kelly (2005: 502-505). 
en Sierra Morena como superiores a las realizadas por ningún otro caballero andante; la espada de don Quijote como más afilada que la de Rolando y que la del emperador Carlos V. Finalmente, los caballeros andantes deberán leer aplicadamente el Amadis, el Palmerín y similares novelas de caballerías como medio de inspiración para la realización de grandes hechos. No hay duda, pues, de la intención burlesca de la pieza. Don Quijote es presentado como un loco objeto de burla cuyas peripecias se aúnan en un argumento plenamente satírico contra el ideal caballeresco. ${ }^{11}$

El contexto de aparición de la obra será fundamental, no obstante, a la hora de interpretar adecuadamente estas primeras adaptaciones de la obra cervantina. En 1613 todavía no ha dado comienzo la guerra de los Treinta Años pero sí asistimos a una Europa dividida en católicos y protestantes. Desde los enfrentamientos de Carlos V con la Liga de Esmalcalda había comenzado la propaganda antiespañola hasta que, finalmente, se extiende una imagen negativa de España entre los protestantes y positiva entre los católicos a nivel internacional, provocándose, así, una serie de alianzas políticas que dividirán a una Europa ya polarizada. ${ }^{12} \mathrm{Si}$ tenemos en cuenta el contexto histórico en el que tiene lugar esta representación no será difícil enmarcar la pieza como parte de la propaganda negativa antiespañola. Federico $\mathrm{V}$ era elector del Palatinado desde 1610 y miembro influyente de la Unión Protestante, una organización fundada por su padre para proteger el protestantismo en el Imperio. Por ello, le ofrecerán la Corona de Bohemia en 1619 en detrimento del católico Fernando II, lo que dará lugar a la Guerra de los Treinta años y al fin de la hegemonía española tras la paz de Westfalia en 1648. Don Quijote reúne en la pieza las características negativas que según el historiador Heinz Schilling son atribuidas por los protestantes en la época al carácter español: anclaje en el pasado medieval, arrogancia, fanfarronería, despotismo y delirios de grandeza hasta la ridiculez. ${ }^{13}$

No escapa, por tanto, al autor de la representación, el potencial del teatro como vehículo de difusión de ideas. Su contexto de aparición no es casual. No en vano el organizador de ambas festividades, Tobias Hübner, pertenecía a los emisarios que negociaban las alianzas matrimoniales en Londres para fortalecer una alianza protestante liderada por el Palatinado contra el emperador católico del Sacro Imperio. ${ }^{14}$ La primera aparición en escena de don Quijote, que a modo de mojiganga, combinaba el entretenimiento de la burla y la enseñanza a partir del contraejemplo del personaje principal, debió de tener éxito, dado que unos meses más tarde Hübner hace salir de nuevo a don Quijote a escena con motivo de la fiesta de un bautizo en Dessau. Además, 
esta vez, una serie de grabados realizados por Andreas Bretschneider ${ }^{15}$ ilustran el texto conservado.

Esta segunda adaptación teatral de temática quijotesca posee una estructura común a la de 1613 de Heidelberg. Se trata de nuevo de un cartel en el que don Quijote expresa las condiciones de su desafío a los participantes del torneo. Don Quijote con un discurso altisonante e hiperbólico insta esta vez a los caballeros «paganos» a medir sus fuerzas contra él. Así deberán hacerlo si se niegan a reconocer a Dulcinea como la más bella. Las expresiones castellanas se introducen de forma constante en el texto: «ihr solt antes tres vezes morir de hambre, als ihr la tierra wider tockiren werdet/Aber/ ich sehe wol der Glanz meines Mambrinischen yelmo [...]» ${ }^{16}$.

Nadie preguntará por su nombre conocido en todo el orbe aunque aun así firma como el ingenioso hidalgo Don Quijote de la Mancha, Caballero de la Triste Figura, señor del extremado caballo Rocinante, coronado de la esperanza e imaginación del Imperio de Trebisonda, derribador y vencedor de los gigantes Caraculiambros, de las islas Malindranias, siervo de la Señora Dulcinea, sin par, del Toboso. Yo el Caballero del Fénix, único, entre muchos. Yo, el derribador de agravios y tuertos, liberador de viudas y pupilos. Yo, el espejo de la caballería, la flor de gentileza, el amigo de la reina Xarilla y querido de la emperatriz Pandafilanda, los deleites de la linda Maritornes. Yo, el amparo y remedio de los menesterosos, el miedo de los tiranos, el espanto de los terribles y la quinta esencia de todos los caballeros andantes. ${ }^{17}$

Al igual que en el caso de Heidelberg, la pieza hace referencia a los episodios más ridículos en los que don Quijote, lejos de toda heroicidad, adapta la realidad a su ficción caballeresca, lo que contribuye a subrayar la burla del héroe cervantino y la falsa percepción que posee de sí mismo. Finalmente, don Quijote se compromete a participar en el torneo siempre que se reconozca que no hay ningún Amadís o Palmerín más poderoso que él, que los libros de caballerías contienen una útil lección y que Dulcinea del Toboso le lleva a cometer las mayores locuras, como la penitencia de Sierra Morena, lo que lo convierte en gran amante, dada la incompatibilidad entre amor y cordura. ${ }^{18}$

La pieza, más extensa que la de Heidelberg, introduce un segundo acto, que contiene la moraleja. Don Quijote recopila las aventuras a las que se hace referencia en las imágenes, como los molinos de viento, el encuentro con Maritornes o el encierro y la vuelta a la aldea para, finalmente, volver a la razón y reconocer los peligros del amor, de la locura y de la ociosidad. La intención fundamentalmente didáctica de la pieza hace que don Quijote no muera sino que extraiga de los hechos la lección aprendida, como haría posteriormente en su traducción Filleau de Saint-Martin. 
A través del discurso irónico y la burla, Don Quijote es presentado en su locura como lo contrario de lo que dice ser: no es valiente sino vanidoso, no es buen amante sino ridículo pretendiente y parodia de los tópicos del amor cortés; no es amparo de los menesterosos sino un peligro; no es el terror de los tiranos sino tirano mismo que pretende imponer su absurda ley a través de las armas. Si se tiene en cuenta el enfrentamiento entre católicos y protestantes en el que se encuentra Europa y que la representación está preparada para uno de los bastiones del protestantismo europeo en festividades tan significativas, la figura de don Quijote puede asociarse de nuevo fácilmente a las cualidades con las que los protestantes identifican a los católicos: anclaje en el pasado medieval, fanfarronería, tiranía, voluntad de imponer la propia ley y fanatismo.

Si analizamos la figura de don Quijote en el grabado de Bretschneider, observaremos como aparece con golilla, que desde el siglo XVII era un atributo frecuentemente utilizado para la burla y parodia del español. ${ }^{19}$ Se trata de la figura central en el desfile de personajes cervantinos que recrea el grabado:

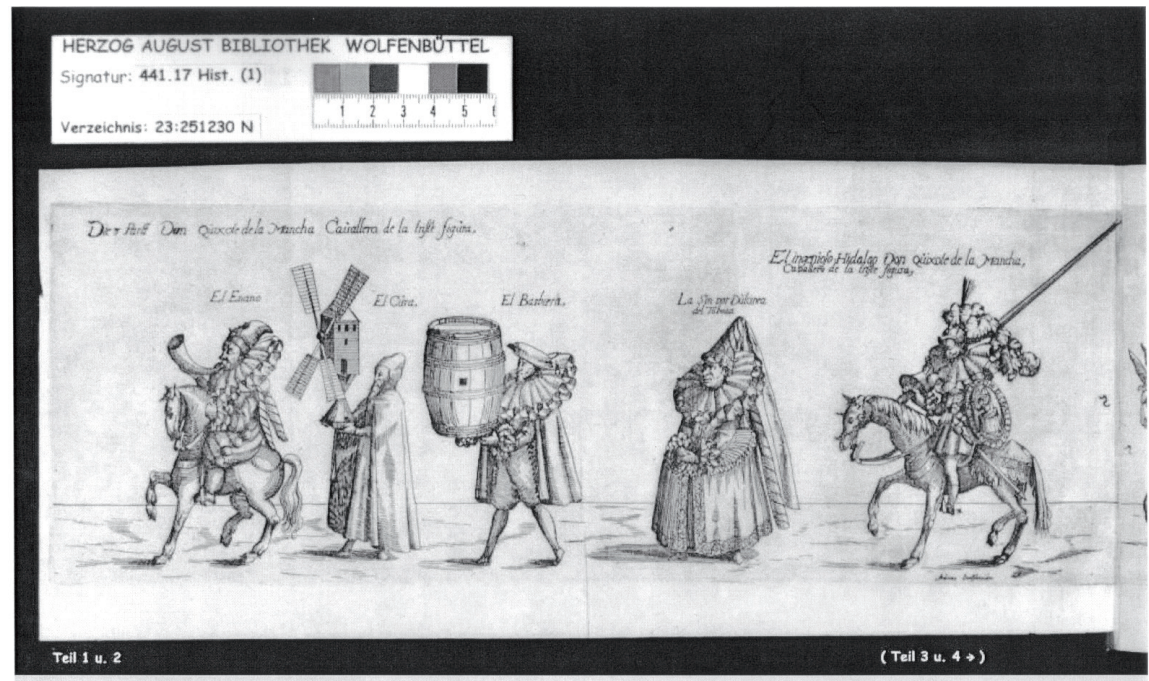

(c) HAB http://diglib. hab.de/drucke/441-17-hist-1/start.htm?image $=00055$ 


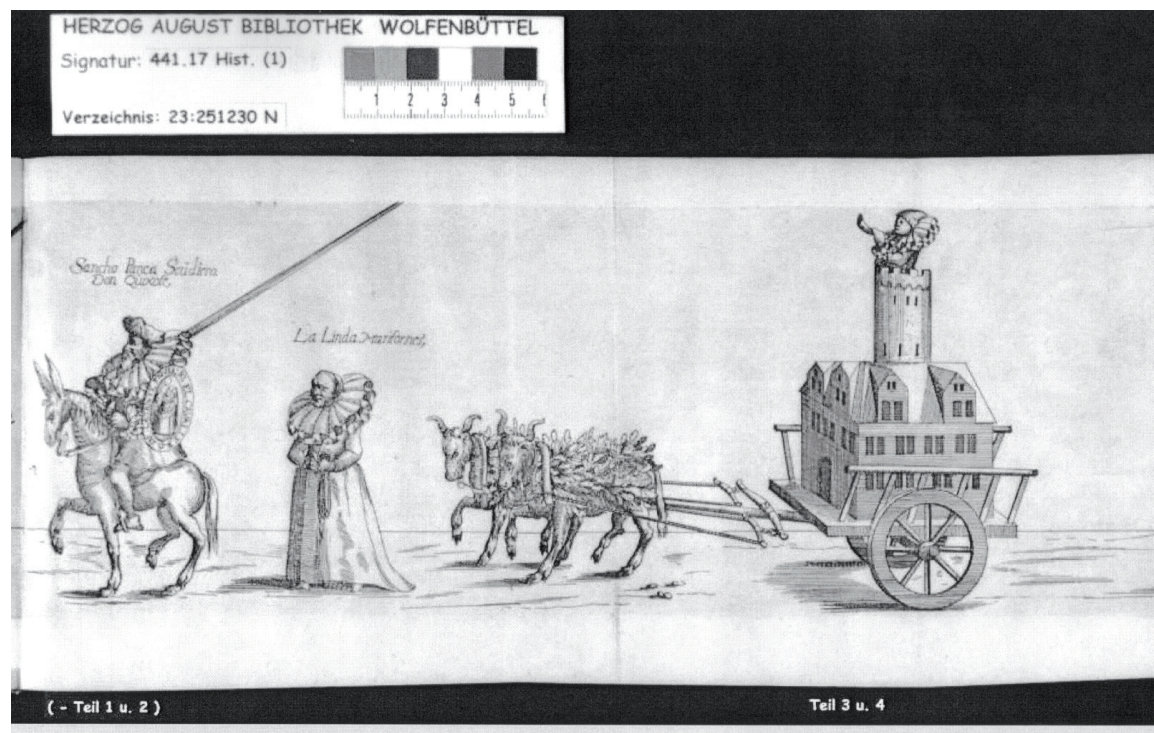

(c)HAB http://diglib.hab.de/drucke/441-17-hist-1/start.htm?image $=00056$

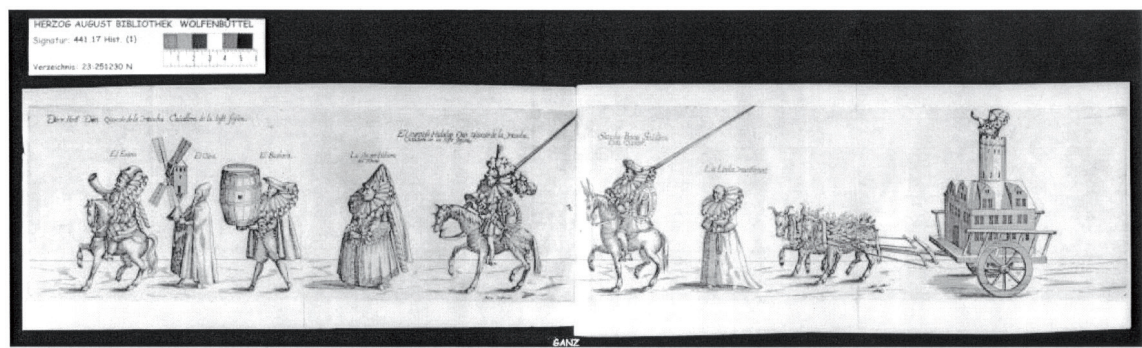

(c)HAB http://diglib.hab.de/drucke/441-17-hist-1/start.htm?image=00056a

A la cabeza se sitúa un enano bufonesco a lomos de un caballo, seguido por el cura que, con un molino en las manos, hace referencia a la conocida aventura relatada en el capítulo VIII de la primera parte. A continuación se encuentran el barbero con un tonel en los brazos y «la sin par Dulcinea del Toboso» vestida con aparatosos atavíos de princesa que no pueden ocultar su rudeza y fealdad. Guarda sus espaldas el valiente Caballero de la Triste Figura con el retrato de Dulcinea en el centro de su escudo, seguido por su fiel escudero Sancho Panza a lomos del rucio, ya armado caballero por don Quijote como premio a sus servicios, ataviado igual que su amo y con el mismo escudo. Cierran filas «la linda Maritornes» y de nuevo un bufón en la torre de un castillo colocada sobre una venta y aludiendo a la conocida confusión de don Quijote de la venta con un castillo. La perspectiva burlesca no deja lugar a dudas: bufones abren y cierran el desfile. El autor se aprovecha, así, de nuevo, del humor burlesco para poner la pieza al servicio de sus propios fines. El humor dista mucho de los principios que determinarán la concepción 
de lo cómico en el XVIII. Lo burlesco va unido aquí a un comportamiento excéntrico y extravagante, que orienta las pasiones, el espíritu y toda la energía del personaje en una misma dirección de tal manera que se hace ridículo. De este modo el escritor burlesco convierte la excentricidad en blanco de las burlas de una determinada comunidad, que con ello consolida mediante la risa su comportamiento aceptado como estándar, confirmándolo, por tanto, como legítimo y válido frente al contraejemplo presentado en escena.

Parece haber sido, por tanto, el factor ideológico más que el estético, el que determinó la selección del Quijote para festividades tan significativas. No es hasta finales de siglo cuando el Quijote inspira las parodias caballerescas de Johann Beer. ${ }^{20}$ Por otra parte, el Quijote se asoció, en algunos casos, a la novela picaresca, ${ }^{21}$ sobre la que las poéticas del barroco guardaban silencio, no sólo porque la novela no pertenecía al canon poético, sino también, en este caso, debido a que el autor culto consideraba que no estaban a la altura de su categoría. ${ }^{22}$ Todo esto pudo haber contribuido a que la presencia del Quijote en el XVII alemán no fuera tan relevante como la de las Novelas ejemplares, que se adaptan mejor al ideal horaciano de prodesse y delectare que domina las reflexiones en torno al género de la época. De este modo, para Harsdörffer, serán más interesantes las Novelas ejemplares, siete de las cuales adaptará, construyéndolas en cuanto a la intencionalidad a modo de sermones secularizados. ${ }^{23}$ Uhlenhart, por su parte, había adaptado Rinconete y Cortadillo en 1617, otorgando un lugar por primera vez a las clases bajas en la literatura alemana. La primera salida a escena del hidalgo manchego en un acontecimiento histórico de tanta relevancia y en fechas tan tempranas destaca, por tanto, especialmente en un siglo que aún no ha visto en el Quijote la obra maestra cervantina.

La primera traducción de la obra en lengua alemana será heredera de esta visión del Quijote y la difundirá a lo largo del siglo. Al igual que en la pieza teatral de 1614, se refiere a la historia de don Quijote como wunderliche Geschichte. La traducción de Basteln von der Sohle, pseudónimo de Joachim Caesar, consta sólo de los 22 primeros capítulos y la primera edición impresa conservada data de 1648 aunque la obra aparecía ya anunciada en diversos

20. Beer parodia la novela de caballerías en el Hoppfen Sack (1678), Adimantus (1678) y en el Ritter Spiridon (1679). La influencia cervantina en estas obras ha sido señalada, entre otros, por Kremer quien afirma que el autor alemán conocía el Quijote y no superficialmente sino de manera profunda, Kremer (1964: 28). Evidencias explícitas de su influencia se encuentran, además, en su mención del Quijote en una de sus polémicas contra Vockerodt y en un episodio del Ritter Spiridon referente al ataque a un molino de viento, Hardin (1983: 19). También Alewyn había hecho referencia a la huella cervantina en Beer aunque matizando, no obstante, que el humor presente en sus parodias caballerescas no posee la complejidad que alcanza con Cervantes o Wieland a través de la convivencia de lo cómico con lo trágico, Alewyn (1932: 238).

21. Esta concepción del Quijote la encontramos, entre otros, en Jean Chapelain (1595-1674) que «ne fait donc aucune différence entre le Lazarillo de Tormes et le Don Quichotte» («que no ve diferencia alguna entre el Lazarillo de Tormes y el Quijote»). Citado por Bardon (1931: 269).

22. Hoffmeister (1980: 98).

23. Strosetzki (2005: 308). 
catálogos desde $1621 .{ }^{24}$ Se trata de una traducción directa del español, que desde el título no deja lugar a dudas sobre el carácter burlesco del contenido del libro: «Don Kichote de la Mantzscha, Das ist: Juncker Harnisch auß Fleckenland [...]». Aunque la traducción es bastante fiel, en el contenido se establecen algunas diferencias resultantes de la interpretación burlesca de la obra. Ya en el mismo título encontramos un buen ejemplo de ello. «La Mancha» no se traduce como topónimo sino como «Fleckenland», es decir como «tierra de las manchas». Señala Germán Colón, asimismo, que el traductor convierte las descripciones objetivas o ligeramente irónicas realizadas por Cervantes en caricaturas grotescas. ${ }^{25}$ Esta intensificación de lo grotesco respecto al original cervantino es característica de estas primeras adaptaciones teatrales a las que venimos haciendo referencia.

La visión burlesca del personaje cervantino se refuerza, al igual que en los textos analizados, con la imagen. Al texto lo acompañan cuatro grabados. El primero alude a la primera comida de don Quijote en la venta; el segundo recrea la lucha del caballero contra los molinos de viento; el tercero, el encuentro nocturno con Maritornes y el cuarto la aventura de los batanes. Se trata, por tanto, de escenas en las que sólo aparece la faceta ridícula del personaje sin viso alguno de heroicidad. Si analizamos brevemente el frontispicio, veremos, en primer lugar, que de nuevo la intensificación del elemento burlesco prima sobre la fidelidad al original. En la imagen, don Quijote no se representa como aquel hidalgo que en el texto cervantino frisaba los cincuenta años sino que el entusiasmo por los ideales caballerescos se asocia más bien al retrato de un caballero joven. La golilla con la que es retratado es un adorno más característico del atuendo de la corte que de un guerrero y utiliza de este modo un atributo para la burla del español del que ya había hecho uso Bretschneider para ilustrar el texto de la pieza teatral. En lugar de una lanza está armado con un palo y el plumaje del casco, alzado en los héroes épicos, aparece aplastado. Monta a un Rocinante escuálido y abatido, recurso burlesco que ya había sido utilizado en la pieza de 1613. Sancho prefiere observar a su amo sin acercarse demasiado mientras mantiene al rucio sujeto con una cuerda. La primera adaptación teatral del Quijote contiene, por tanto y como anunciábamos al comienzo del estudio, los rasgos fundamentales de la interpretación del Quijote en el XVII alemán plasmada y difundida en la primera traducción de la obra a la lengua alemana: interpretación meramente burlesca de la obra, intensificación de lo grotesco respecto al original cervantino, extrapolación de la burla a la nación española, atención prácticamente exclusiva al personaje de don Quijote, presentado desde una perspectiva siempre grotesca y desinterés por el autor de la obra. 


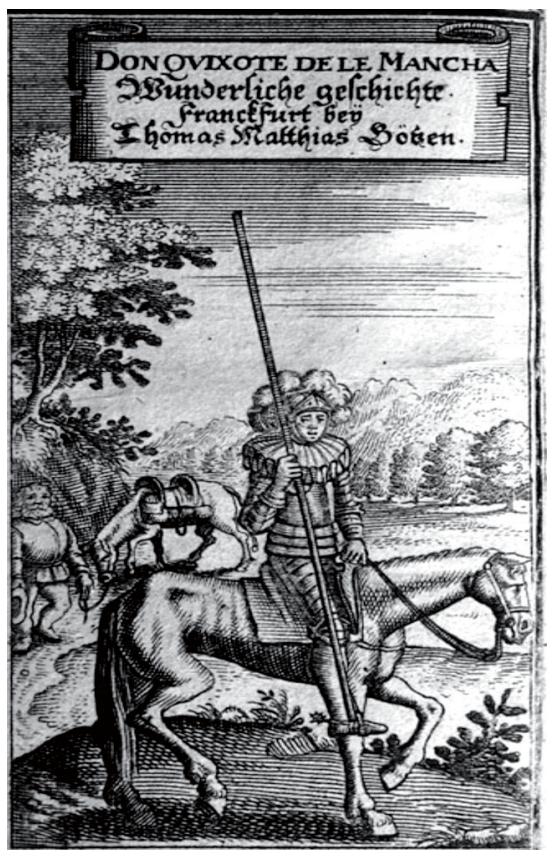

La burla quijotesca asociada a la nación española es la clave interpretativa del humanista Christian Thomasius (1655-1728), que ve en el Quijote una fuerte carga satírica que puede ser utilizada con afán didáctico (como sin duda se hiciera en la pieza de 1614) para promover, de una parte, la reforma del absolutismo protestante y, de otra, la ruptura con las medievales creencias católico-romanas. La sátira del Quijote trascendería, por tanto, su ámbito originario y alcanza dimensiones plenamente actuales en el enfrentamiento entre protestantismo y catolicismo. ${ }^{26} \mathrm{La}$ interpretación de Thomasius es, para Parada, excepcional por dos motivos: en primer lugar por el valor pedagógico que atribuye a la sátira, con lo que se anticipa a la interpretación del Quijote de la temprana Ilustración y por reconocer en el Quijote una sátira de carácter universal trasladando su objetivo a la situación histórica del momento con afán constructivo. Esta será la interpretación de la obra cervantina de la temprana Ilustración hasta que, aproximadamente en el segundo tercio de siglo XVIII, una nueva corriente de pensamiento $\mathrm{y}$, con ella, una nueva concepción de la literatura, den un giro de 180 grados a la interpretación de la obra cervantina. ${ }^{27}$ (2011).

27. Para la interpretación del Quijote en la Alemania del siglo XVIII, véase, Rivero iglesias 


\section{BIBLIOGRAFÍA}

Alewyn, R. (1932). Johann Beer. Studien zum Roman des 17. Jahrhunderts, Leipzig, Mayer \& Müller.

Bardon, M. (1931). Don Quichotte en France au XVIIe et au XVIIIe siècle. 1605-1815, Paris, Librairie Ancienne Honoré Champion.

Briesemeister, D. (2010). «Über Don Quijotes Ausritte in die Welt der Bilder: Von Festaufzügen des frühen 17. Jahrhunderts bis zum Bildwerk Eberhard Schlotters», Don Quijotes intermediale Nachleben/ Don Quixote's intermedial Afterlives, Ed. Ines Detmers y Wolfgang G. Müller, Trier, Wissenschaftlicher Verlag, pp. 95-121.

Briesemeister, D. (2011). «La primera salida a escena de don Quijote en Alemania», Ortodoxia y heterodoxia en Cervantes, Ed. Carmen Rivero Iglesias, Alcalá de Henares, Centro de Estudios Cervantinos, pp. 319-328.

(1614). Cartel, Auffzüge, Vers und Abrisse, so bey der fürstlichen Kindtauff ... freudenfest zu Dessau .... In gehaltenem Ringel und Quintanen Rennen, auch Balletten und Tänzen, den verordneten Herrn Judicierern, Leipzig, in Henning Grossen des ältern Druckerey verfertiget.

Colón, G. (1974). Die ersten romanischen und germanischen Übersetzungen des Don Quijote, Bern.

(1997). Etymologisches Wörterbuch des Deutschen, Ed. Wolfgang Pfeifer, München.

Fischer, H. (1892). «Don Quijote in Deutschland», Vierteljahrschrift für Literaturgeschichte, V, pp. 331-332.

Gabel, G. U. (2005). Don Quijotes Spuren in Deutschland. Materialien zur Rezeptionsgeschichte , Köln, Universitäts- und Stadtbibliothek.

Hardin, J. N. (1983). Johann Beer, Boston, Wayne Publishers.

Heller, J. (1831). Monogrammen Lexicon, enthaltend die bekannten, zweifelhalften und unbekannten Zeichen, so wie die Abkürzungen der Namen der Zeichner, Maler, Formschneider, Kupferstecher, Litographen, usw. Mit kurzen Nachrichten über dieselben, Bamberg, Sickmüller.

Hoffmeister, G. (1980). España y Alemania. Historia y documentación de sus relaciones literarias, Madrid, Gredos.

Hübner, T. (1613). Beschreibung der Reiß [...] mit schönen Kupfferstücken gezieret, Gotthardt Vögelins Verlag.

Kremer, M. (1964). Die Satire bei Johann Beer, Düsseldorf, bei Rudolf Stehle.

Parada, A. (1997). Offene literarische Welten gegen geschlossene Denkmodelle und Sozialsysteme.' Don Quijote' und 'Anton Reiser', Frankfurt am Main, Vervuert.

Rivero Iglesias, C. (2011). La recepción e interpretación del Quijote en la Alemania del siglo XVIII, Colección Casasayas, Ayuntamiento de Argamasilla de Alba, Diputación Provincial.

Sánchez Jiménez, A. (2002). «Cuellos, valonas y golillas: leyes suntuarias y crítica política en No hay mal que por bien no venga, de Juan Ruiz de Alarcón», Bulletin of the Comediantes, 54, pp. 91-113.

Schilling, H. (2002). «Del Imperio común a la leyenda negra: la imagen de España en la Alemania del siglo XVI y comienzos del XVII», Ed. M. Á. Vega Cernuda y H. Wegener, España y Alemania: percepciones mutuas de cinco siglos de historia, Madrid, Complutense, pp. 37-78.

Strosetzki, C. (2005). «Alemania», Gran Enciclopedia Cervantina, dir. Carlos Alvar, Vol. I, Madrid, Centro de Estudios Cervantinos-Castalia, pp. 304-322. 
Watanabe-O'Kelly, H. (2005). «Turniere», Höfe und Residenzen im spätmittelalterlichen Reich. Bilder und Begriffe, Ed. W. Paravicini, Ostfildern, Jan Thorbecke Verlag, pp. 502-505.

Recibido: 20 de enero de 2012

Aceptado: 17 de enero de 2013

\begin{abstract}
Resumen
El presente estudio analiza las primeras apariciones de don Quijote en la escena alemana para mostrar en qué medida determinan la recepción de la obra cervantina en el siglo XVII alemán. Estos primeros espectáculos de Heidelberg (1613) y Dessau (1614) proyectan una interpretación del Quijote que intensifica lo grotesco con respecto al original cervantino y que extrapola esa burla a la nación española en un contexto de enemistad política y religiosa entre católicos y protestantes. La primera traducción alemana sería heredera de esta concepción de la obra cervantina que iría transformándose y ganando matices hasta el segundo tercio del siglo XVIII cuando el cambio de coordenadas históricas y la irrupción de la individualidad y del genio transforman por completo su interpretación.
\end{abstract}

Palabras clave: Quijote; recepción; Alemania; siglo XVII.

Title: The first theatrical adaptations of the Don Quixote and the beginning of Cervantes.

\begin{abstract}
The present study analyzes the first appearances of Don Quixote on German stages. The goal is to illustrate how these theatrical performances determine the reception of Cervantes' work in $17^{\text {th }}$ century Germany. The first performances in Heidelberg (1613) and Dessau (1614) display an interpretation of Don Quixote, which intensifies the grotesque dimension of Cervantes' original. Its satire is transformed into a satire of Spain in a context determined by political and religious animosity between Catholics and Protestants. The first German translation inherited this conception of Cervantes' work. This conception would acquire new shades until middle of the $18^{\text {th }}$ century, when the alteration of historical coordinates and the rise of individuality and genius thoroughly transformed its interpretation.
\end{abstract}

Key words: Don Quixote; Reception; Germany; 17th Century. 